\title{
MEDICALIZAÇÃO DA APRENDIZAGEM E RESILIÊNCIA: SIGNIFICAÇÕES PRODUZIDAS NA ESCOLA
}

\author{
MEDICALIZACIÓN DEL APRENDIZAJE Y RESILIENCIA: \\ SIGNIFICACIONES PRODUCTIVAS EN LA ESCUELA
}

\author{
MEDICALIZATION OF LEARNING AND RESILIENCE: SIGNIFICATIONS \\ DEVELOPED IN SCHOOLS
}

\author{
Regina Lemes dos SANTOS ${ }^{1}$ \\ Francismara Neves de OLIVEIRA ${ }^{2}$ \\ Luciane Guimarães Battistella BIANCHINI ${ }^{3}$
}

RESUMO: O artigo discute a promoção de resiliência a partir da análise das significações produzidas no contexto de alunos diagnosticados com Transtorno de Déficit de Atenção e Hiperatividade (TDAH) que fazem uso do Cloridrato de Metilfenidato. O modelo Bioecológico do Desenvolvimento Humano foi adotado como aporte teórico-metodológico. A pesquisa optou pela abordagem qualitativa de cunho descritivo-interpretativo e contou com a participação de 40 pessoas, a saber: profissionais da saúde (1 neuropediatra, 1 psicólogo); profissionais da educação (5 pedagogos, 11 professores); 10 alunos e 12 familiares. Os dados foram coletados mediante entrevista no contexto de seis escolas municipais de uma cidade norteparanaense. Os resultados indicaram a necessidade de repensar as práticas avaliativas correntes e revelaram que o processo diagnóstico é demarcado por fatores de risco e de proteção, os quais afetam o processo de aprendizagem escolar. Os dados permitiram inferir que a promoção da resiliência, nesta situação, pode resultar no estabelecimento de redes protetivas, maior inter-relação entre os profissionais de saúde e educação e suporte efetivo aos familiares e alunos usuários do medicamento. Esse contexto resultaria em condições mais favoráveis à vinculação do aluno à escola e a mudanças positivas no processo de aprendizagem escolar dos alunos diagnosticados com TDAH.

PALAVRAS-CHAVE: Resiliência. Teoria bioecológica do desenvolvimento humano. TDAH. Medicalização da aprendizagem. Ritalina.

RESUMEN: El artículo discute la promoción de resiliencia a partir del análisis de las significaciones producidas en el contexto de alumnos diagnosticados con Transtorno por Déficit de Atención e Hiperactividad (TDAH) que hacen uso del Clorhidrato de Metilfenidato. El modelo bioecológico del Desarrollo Humano se adoptó como aporte

${ }^{1}$ Universidade Estadual de Londrina (UEL), Londrina - PR - Brasil. PPG em Educação. ORCID: <http://orcid.org/0000-0002-3928-6021>. E-mail: regi_ped@ hotmail.com

${ }^{2}$ Universidade Estadual de Londrina (UEL), Londrina - PR - Brasil. Professora Associada do Departamento de Educação e Programa de Pós-graduação em Educação. Pós-Doutora em Psicologia pela USP. ORCID: <http://orcid.org/0000-0002-0809-2304>. E-mail: francis.uel@gmail.com

${ }^{3}$ Universidade Norte do Paraná (UNOPAR) - PR - Brasil. Docente do Programa de Pós-graduação em Metodologias para o Ensino de Linguagens e suas Tecnologias. Pós-Doutora em Psicologia pela UNESP. ORCID: <http://orcid.org/0000-0003-3523-2752>. E-mail: luannbi@ hotmail.com. 
teórico-metodológico. La investigación optó por el abordaje cualitativo de cuño descriptivo-interpretativo y contó con la participación de 40 personas, a saber: profesionales de la salud (1 neuropediatra, 1 psicólogo); Profesionales de la educación (5 pedagogos, 11 profesores); 10 alumnos y 12 familiares. Los datos fueron recolectados mediante entrevista en el contexto de seis escuelas municipales de una ciudad norte-paranaense. Los resultados indicaron la necesidad de repensar las prácticas evaluadoras corrientes y revelaron que el proceso diagnóstico es demarcado por factores de riesgo y de protección, los cuales afectan el proceso de aprendizaje escolar. Los datos permitieron inferir que la promoción de la resiliencia, en esta situación, puede resultar en el establecimiento de redes de protección, mayor interrelación entre los profesionales de salud y educación y apoyo efectivo a los familiares y alumnos usuarios del medicamento. Este contexto resultaría en condiciones más favorables a la vinculación del alumno a la escuela ya cambios positivos en el proceso de aprendizaje escolar de los alumnos diagnosticados con TDAH.

PALABRAS CLAVE: Resiliencia. Teoría bioecológica del desarrollo humano. TDAH. Medicalización del aprendizaje. Ritalin.

ABSTRACT: This paper broaches the promotion of resilience by analyzing significations developed within the context of students diagnosed with Attention Deficit Hyperactivity Disorder (ADHD) using the medicine methylphenidate hydrochloride (Ritalin or Concerta) The Bio-ecological model of Human Development was adopted as a theoretical-methodological contribution. The research followed the qualitative approach of descriptive-interpretative nature comprising 40 people, namely: health staff (1 neuropediatrician, 1 psychologist); education staff (5 pedagogues, 11 teachers); 10 students and 12 family members. The data were collected by means of interview within a context including six county schools in a Northern Parana State town. The results pointed out the need to rethink the current assessment practices and showed that the diagnostic process is defined both by risk factors and protection, which affect the school learning process. The data allowed us of conclude that the promotion of resilience, under that circumstance, may result in the establishment of affective support networks provided to family members and students using that medicine. Such a context would result in conditions more favorable to link the student to the school and positive changes in the school learning process of students diagnosed with ADHD.

KEYWORDS: Resilience. Bio-ecological theory of human development. ADHD. Medicalization of learning. Ritalin.

\section{Introdução}

A administração de medicamento a grande número de crianças brasileiras tem alertado para a necessidade de estudos acerca do fenômeno da medicalização e sua relação com o aprender. Itaborahy (2009) anuncia que o aumento da produção de Cloridrato de Metilfenidato - princípio ativo da Ritalina -, no Brasil, tem acompanhado o aumento do seu consumo por crianças/adolescentes nos últimos anos. Crianças e 
adolescentes que fazem uso deste medicamento comumente possuem um histórico de reprovação, abandono escolar e/ou dificuldades de escolarização, muitas vezes associados à indisciplina na sala de aula. Essa lógica tem marcado presença nos contextos escolares e tem sinalizado que as dificuldades de escolarização são exclusivas do aluno, decorrentes da sua indisciplina e descompromisso com os saberes escolares.

No presente artigo, relacionamos essa questão ao fenômeno da resiliência no contexto de alunos diagnosticados com Transtorno de Déficit de Atenção e Hiperatividade (TDAH). Para tal, fez-se necessário conhecer os significados produzidos por diferentes sujeitos que vivenciam o processo de medicalização da aprendizagem em um contexto escolar específico. Com base nos significados produzidos nos diferentes lugares sociais que constituem o contexto analisado (profissionais de saúde, de educação, familiares e alunos) procuramos identificar os fatores de risco e proteção, pois, segundo o referencial teórico adotado (Teoria Bioecológica do Desenvolvimento Humano), eles coexistem, impactando a trajetória de vida da pessoa de modo negativo ou positivo (POLETTO; KOLLER, 2008).

Adotamos a Teoria Bioecológica do Desenvolvimento Humano como aporte teórico e metodológico deste estudo, pois evidencia que os fenômenos demandam ser compreendidos a partir de uma rede de sentidos, contidos em seu contexto de origem. Esse modo de perceber os fenômenos permite compreender que eles se desencadeiam com base nas relações interpares e o ambiente, de modo recíproco. Anunciando, portanto, que o desenvolvimento humano é explicado pela inter-relação de quatro elementos: processo, pessoa, contexto e tempo.

O processo, corresponde ao mecanismo definidor do desenvolvimento humano, contempla as interações da pessoa progressivamente mais complexas, ao longo do tempo, com outras pessoas, objetos e símbolos existentes no seu ambiente imediato. Os processos proximais, dependendo da natureza do ambiente, podem promover dois efeitos sobre a pessoa: competência e disfunção.

A pessoa desempenha papel ativo nos processos proximais e suas características (biológicas, cognitivas, emocionais e sociais) são consideradas como produto e produtoras parciais no seu processo de desenvolvimento.

O contexto é constituído pelo conjunto de quatro sistemas interconectados. O microssistema representado pelo ambiente imediato em que ocorrem interações face a face: família e escola, por exemplo. O mesossistema consiste no conjunto de dois ou mais microssistemas que se inter-relacionam e a pessoa participa ativamente, como no 
caso das relações estabelecidas no âmbito da família e da escola; da família e da igreja. O exossistema é caracterizado pelo contexto no qual a pessoa não é participante ativa, mas tem seu desenvolvimento afetado pelos eventos que nele ocorrem. E o macrossistema, de maior alcance, pois engloba os demais e é representado pelas ideologias, crenças, religiões e valores, os quais exercem influências sobre o modo de vida das pessoas.

O tempo ou também chamado de Cronossistema, marca os movimentos dos processos proximais. Ele condiciona o impacto, a influência e o sentido dos eventos na vida de um indivíduo ou população, e é caracterizado por diferentes intervalos de tempo: tempo imediato, dias, semanas e anos. Assim, ao serem estudadas as práticas medicalizantes da aprendizagem escolar, a voz dos diferentes protagonistas deste contexto é destacada, pois faz emergir um conjunto de significados próprios a um tempo e um espaço de interações e permite que neste contexto sejam encontradas relações com a promoção da resiliência na escola.

O tema da resiliência em Educação é relevante à pesquisa, pois a instituição escolar representa um microssistema complexo que impacta o desenvolvimento humano, decorrente das significações ali produzidas, tanto pelos sujeitos que o constituem diretamente (profissionais da Educação e alunos), como pelos sujeitos com os quais a escola interage, familiares e profissionais da saúde, por exemplo, em parcerias firmadas com a escola, como é o caso do contexto analisado.

A literatura nacional disponível revela a importância de estudos que estreitem a relação escola+família, escola+saúde, escola+comunidade, no que diz respeito à produção de resiliência. Neles há indicação de que os contextos escolares investigados apresentam, em relação de correspondência, fatores de risco e de proteção, e a escola é enfatizada como ambiente favorável à produção de resiliência (POLETTO; KOLLER, 2008; SCRIPTORI; BORGES JÙNIOR, 2010; LIBÓRIO, 2009; OLIVEIRA; MACEDO, 2011; BAZONI, 2014).

Nesse sentido, a medicalização da aprendizagem e as significações atribuídas ao uso de medicamento como condição para aprender, no caso de alunos diagnosticados com TDAH é tomado como objeto de estudo para investigar possibilidades de promoção de resiliência neste contexto.

\section{Resiliência: processo de enfrentamento positivo em contexto de medicalização do aprender}


Os primeiros estudos realizados pela Psicologia referentes à resiliência compreendiam que o equilíbrio psíquico, em resposta às adversidades da vida, consistia em uma característica intrínseca, própria de algumas pessoas. Entretanto, estudos posteriores consideraram a existência de processos positivos presentes nas relações que as pessoas estabelecem em contexto e com outras pessoas, as quais influenciam os significados que atribuem ao vivido, constituindo modos de enfrentamento positivo. Assim, as vivências do sujeito ao mesmo tempo que influenciam são influenciadoras dos contextos nos quais está inserido e dizem respeito às interações com pessoas, objetos e símbolos presentes. A resiliência assume, assim, sentido relativo, pois se relaciona às inter-relações no contexto e às circunstâncias que o constituem (RUTTER, 1985 apud YUNES; SZYMANSKI, 2002; YUNES; JULIANO, 2010).

Yunes (2003) discorre sobre a necessidade de pensar a resiliência pela perspectiva dos aspectos sadios e de sucesso experienciados pelos sujeitos, os quais contribuem positivamente para o processo de enfrentamento da adversidade vivida. Para a autora, pensar a vida pelo viés dos aspectos saudáveis tem mais sentido que enfatizar os desajustes e falhas que estão presentes nas relações que o sujeito estabelece em contexto. A resiliência em contexto permite minimizar os riscos do discurso classificatório que desconsidera a possibilidade do sujeito elaborar e desenvolver estratégias de enfrentamento no contexto em que está inserido e nele estabelecer algum tipo de interação que favoreça seu processo de desenvolvimento.

A abordagem ecológica de Bronfenbrenner, por sua vez, caracteriza-se como um modelo teórico que dá visibilidade à resiliência por processo. Isto porque nela são consideradas as relações interpares e o ambiente, onde a resiliência pode estar presente. De acordo com Bazoni (2014, p. 31), “[...] o ambiente e seus componentes fazem parte do fenômeno em processo e compreendem a relação entre o contexto e as características da pessoa em desenvolvimento".

De acordo com Cyrulnik (2001), o enfrentamento das condições adversas também é decorrente da mobilização de recursos internos e externos de que a pessoa dispõe. Assim, pessoa e processo se integram. O processo envolve fatores que interagem de forma constante e que, conforme Benetti e Crepaldi (2012, p. 16), “[...] agem no processo de resiliência como fatores protetivos ou de risco, facilitando e potencializando (positivamente/negativamente) os eventos presentes na vida do indivíduo [...]". 
A natureza processual da resiliência passa a ser anunciada a partir de um jogo de forças que decorre da relação entre os fatores de risco e proteção presentes no contexto, os quais podem influenciar negativa ou positivamente os modos de produção de sentido das pessoas acerca de um dado evento. Aqueles eventos que podem acarretar prejuízos ao desenvolvimento e à existência da pessoa são caracterizados como fatores de risco. Este potencializa as chances de desestabilizar a vida do indivíduo, de grupos e comunidades, pois pode comprometer o processo de desenvolvimento humano e as relações que são estabelecidas em contexto (YUNES; SZYMANSKI, 2002; MORAIS; KOLLER, 2004).

Entretanto, os efeitos do risco podem ser minimizados por intermédio das respostas que emergem das relações que a pessoa estabelece em contexto e isto se constitui resiliência. Essa capacidade de "neutralizar" o impacto negativo da adversidade e oferecer suporte ao processo de enfrentamento da pessoa é denominada fator de proteção (RUTTER, 1985 apud YUNES; MIRANDA; CUELO, 2004). O sentido de proteção pode ser caracterizado pelos vários efeitos que podem favorecer a mudança da trajetória de vida do indivíduo frente ao risco, influenciando-a positivamente ao possibilitar a produção de respostas de caráter protetivo.

Isto posto, refletir acerca do processo de medicalização do aprender na escola parece fazer sentido e mostra-se relevante, dada a intenção de identificar estratégias de resiliência nesse contexto. Assim, manifesta-se a necessidade de resgatar os fatores protetivos presentes na relação de ensinar e aprender, os quais podem ser promotores do desenvolvimento do aluno.

De acordo com Collares e Moysés (2011, p. 25), a medicalização decorre do “[...] processo de transformar questões não-médicas, eminentemente de origem social e política, em questões médicas, isto é, tentar encontrar no campo médico as causas e soluções para problemas dessa natureza”. Segundo as considerações das autoras, as questões de ordem social e política passam a ser subsumidas como de ordem individual. Estrutura-se um discurso indicador de que o problema é exclusivo do aluno e que enfrentamento mais acertado é tratar o sintoma em lugar das causas favorecedoras da sua manifestação. Na medida em que é atribuído sentido de transtorno às respostas (sintomas) humanas ao que não vai bem, resta o tratamento terapêutico e/ou farmacológico, inclusive ao processo de aprender.

Bonadio (2013, p. 123) lembra que: "Medicar as dificuldades na escolarização retira as possibilidades de analisar criticamente a qualidade das escolas, a formação dos professores, a precariedade das políticas educacionais e o pouco investimento na 
educação". A resiliência como processo e as práticas medicalizantes no contexto escolar podem nos indicar que as interações que ocorrem entre as pessoas e seus contextos, possibilitam a elaboração de significações acerca do vivido. Deslocar o olhar de pontos isolados do contexto e visualizar a integração dos elementos sistemicamente envolvidos pode favorecer o alcance das relações que se estabelecem entre eles, bem como a análise dos fatores de risco e de proteção que constituem o contexto.

\section{Caminhos percorridos na pesquisa}

A pesquisa, de abordagem qualitativa, foi desenvolvida na modalidade de estudo descritivo (GIL, 2008). Ao adotar a perspectiva bioecológica do desenvolvimento humano como aporte teórico-metodológico, enfatizou a produção dos sentidos em contexto (YUNES; MIRANDA; CUELLO, 2004).

Analisamos os modos de conceber e lidar com o processo diagnóstico, materializado na relação encaminhamento-diagnóstico-prescrição de medicamento, apresentado no recorte escolhido para discussão neste artigo - as significações produzidas por diferentes grupos de sujeitos (profissionais da educação, profissionais da saúde, familiares e alunos), envolvidos em um contexto no qual a medicalização da aprendizagem ocorre - e, assim, identificar os fatores de risco e proteção presentes.

Foram selecionados 40 participantes: 1 psicólogo, 1 neuropediatra; 5 pedagogas, 11 professores; 10 alunos, 12 familiares. Os alunos e respectivos familiares são assistidos pelos profissionais de saúde participantes da pesquisa e atendidos na escola pelos professores e pedagogos que também compuseram o grupo de participantes do estudo. Foram envolvidas seis escolas municipais de meio urbano de um município no estado do Paraná. Adotamos a entrevista como instrumento de pesquisa e o software MaxQDA como organizador dos dados coletados, facilitando a sua manipulação, para análise dos achados da pesquisa.

\section{Os participantes, seus lugares no contexto e as significações atribuídas ao aluno diagnosticado e ao atendimento prestado - Significações produzidas acerca do aluno diagnosticado com TDAH}

Apresentamos, neste artigo, dois eixos de análise que revelam significações presentes no contexto estudado. Em primeiro lugar, aquelas atribuídas aos alunos diagnosticados com TDAH e que fazem uso da medicação (metilfenidato) e, 
posteriormente, as significações atribuídas ao processo de encaminhamento, passando pelo diagnóstico até a prescrição do uso do medicamento. Considerando como o aluno com TDAH é percebido neste contexto, destacamos alguns depoimentos representativos das significações produzidas nos diferentes lugares sociais do contexto, ocupados pelos distintos participantes do estudo.

No relato dos participantes do grupo de "profissionais da educação" (pedagogos e professores), as características atribuídas ao sujeito com TDAH são recorrentes, expressas por meio de uma lista de comportamentos inadequados às condições de aprendizagem: "desorganizado" (PE1), "fala o tempo todo" (PE2), "falta de interesse" (PE3), “agitação” (PE4, P11), "sem limites” (PE5), “não prestam atenção” (P1, P6), “agressivo” (P2, P4), “estabanada, desengonçada” (P3), "barulhento” (P5), “atrapalham” (P7), “irritado” (P8, P10). As falas dos participantes parecem indicar que esse aluno diagnosticado é percebido como um problema para as relações que estabelece com seus pares no contexto da escola.

No grupo dos 'profissionais da saúde', destaca-se o modo como a psicóloga caracteriza os alunos com TDAH, que sugere correspondência com as queixas que lhe chegam pelos profissionais da escola e que, segundo a psicóloga, são conferidas por ela de acordo com aquelas indicadas no Manual Diagnóstico e Estatístico de Transtornos Mentais - DSM IV (vigente no momento em que os dados do estudo foram coletados).

A psicóloga menciona que encaminha antecipadamente à escola um formulário, a ser respondido pelo professor, referente às dificuldades escolares da criança. "A gente faz um levantamento através de um teste formal da psicologia - são perguntas e respostas direcionadas ao professor com respeito à conduta da criança” (PS). É a psicóloga quem avalia a pertinência do atendimento pelo neuropediatra.

Neste contexto, é possível perceber um encadeamento de ações entre os profissionais da educação e a psicóloga, antes que ocorra o encaminhamento do aluno para o neuropediatra. Há, aqui, duas questões a serem discutidas: uma delas indica proteção - integração entre profissionais da Educação e da Saúde; e a outra indica risco - encadeamento e confirmação de uma listagem de sintomas atribuídos ao TDAH. Existência de um check list confirmador de um conjunto de sintomas. O fato de que o professor preenche um formulário, sem contato com a psicóloga que faz a avaliação, não se constitui processo integrado. Igualmente, ter ciência de que o neuropediatra está acompanhando o caso não torna as ações destes profissionais multidisciplinares. Esses 
aspectos constituem risco, do ponto de vista das discussões que realizamos e da postura da literatura que trata da resiliência como processo.

Para o neuropediatra, o perfil do aluno é evidenciado na fala: "Ansiedade, manias, dificuldade de lidar com frustração, problemas relacionados à inadequação social, comportamentos anti-sociais [...] Então a gente melhora tudo isso com a prescrição do medicamento" (NP). Depreende-se que as referidas características atribuídas ao aluno não constituem a melhor forma dele inserir-se nos contextos e constituir-se como pessoa.

Isto posto, questionamos: $\mathrm{O}$ que pode vir a ser entendido como comportamento antissocial? A agitação na sala de aula? A dificuldade de autocontrole? A agressividade que pode ser decorrente de seu isolamento e segregação recorrentes? A dificuldade de lidar com frustração em uma história de vida marcada pela rejeição?

Barbarini (2011, p. 109) assinala que “[...] os diagnósticos e os tratamentos silenciam a verdade da criança e toda a sociedade recria sua imagem como um desviante, um perigo, uma ameaça que deve ser contida para o bem dos outros e para o seu próprio". Assim, alunos diagnosticados com TDAH têm sido silenciados, sobretudo pela imagem socialmente construída a respeito deles, validada no 'checklist' que ignora as singularidades desses sujeitos, pela medicação.

Reconhecemos que os efeitos desses comportamentos na dinâmica escolar são danosos, pois alteram o funcionamento e dificultam o trabalho do professor. Entretanto, é preciso estar alerta quanto ao diagnóstico e ao rótulo que dele decorre quando a história de vida do aluno e o mapeamento do contexto escolar são desconsiderados.

No "grupo de familiares", as significações produzidas acerca das características dos alunos (filhos) diagnosticados com TDAH remetem a comportamentos que prejudicavam as relações com seus pares, na escola e na família: "não parava” (F1), "não prestava atenção" (F2, F12), "num fazia tarefa" (F3), "era agressivo" (F6, F8, F10). Para os familiares, a relação com a criança diagnosticada com TDAH aparece marcada por sentimento de impotência e frustração, especialmente porque as repreensões dos profissionais da escola indicam que eles são omissos no processo de cuidado e educação da criança. Nesse sentido, as qualificações atribuídas ao aluno passam a constituir risco, pois acionam o alerta (estigma do diagnóstico) às relações (BARBARINI, 2011).

Considerando a teoria Bioecológica de Bronfenbrenner (1986, 2011), evidenciase que a identidade não se constitui somente baseada nos atributos próprios da pessoa, 
pois ela recebe influências do meio social. A pessoa internaliza as ideias e os conceitos que são elaborados a seu respeito e, assim, passa a ressignificar a própria imagem.

De acordo com o "grupo de alunos", o modo como se percebem nas interações que estabelecem no contexto familiar parece ser positivo, pois afirmam que são considerados em casa como bons filhos. A fala de $\mathrm{A} 2$ faz referência à sua autoestima e a de A5 ao critério de normalidade, que o iguala aos demais alunos da sala de aula: "Acham eu bonito", "trabalhador" (A2), "acham que eu sô uma criança normal" (A5). As falas evidenciam o quanto as impressões do adulto interferem na percepção que a pessoa elabora de si mesma.

Os alunos participantes também declaram que são considerados 'bons alunos'e sabem disso porque os adultos lhes falam a respeito: "por causa das notas que eu tô tirano" (A2); "que eu me comporto" (A5), "faço as coisas que a tia fala" (A7). A melhoria das notas e do comportamento aparece correlacionada ao avanço no desempenho acadêmico. Nestas condições, o fato dos alunos entrevistados terem se mostrado permeáveis à atuação do outro e desejado essa interação, constituem fatores protetivos.

Outro aspecto a destacar nas significações, produzidas a partir dos diferentes lugares sociais dos participantes no contexto, é o determinismo biológico na atribuição das causas para o não aprender que, de acordo com a antropologia, é concebido como um tipo de doutrina que prega a ideia de que as ações humanas são determinadas por questões de ordem biológica, desconsiderando outros elementos que atuam no seu processo de desenvolvimento e influenciam os modos de se inserir nos contextos (LARAIA, 2001).

Indícios desse tipo de discurso foram observados nos depoimentos de pedagogos e professores, com ênfase nos aspectos biológicos no diagnóstico do TDAH, indicando que ‘o aluno é...': “eles são agitados”, “são distraídos” (PE3), “são agressivos”, “não consegue se concentrá” (P6). Assim, o diagnóstico de TDAH permite, de certo modo, legitimar e cristalizar a ideia de que o aluno não consegue, por si só, controlar o comportamento, pois é portador de um transtorno, portanto necessita ser tratado com medicamento.

As significações dos 'profissionais da saúde' também anunciam o modo determinista de perceber o sujeito com TDAH. A psicóloga faz menção ao modo como procede no atendimento do aluno: "A gente faz a avaliação nela (criança)". Essa frase revela um olhar que localiza no aluno o problema. Por meio de um protocolo de 
checagem de sintomas, o aluno é diagnosticado como tendo 'nele' uma justificativa para o não aprender.

A visão determinista do sujeito também consta na fala do neuropediatra, ao afirmar que o problema é biológico, mas que basta ser tratado: "Muitas crianças descobrem: 'eu tenho uma dificuldade especifica que basta tratar e eu vou conseguir dar conta da escola e da minha vida em casa", (NP). Entretanto, está implícito que há um problema de ordem biológica que explica os desajustes no processo de aprender, pressupondo que a aprendizagem seja resultante da condição biológica do sujeito. Isto posto, a medicação passa a ser a condição para que o sujeito aprenda.

De acordo com Luengo (2009, p. 97), a construção social do sintoma é desconsiderada, enquanto o sintoma individual é legitimado: “[...] reduzindo-a a um ser que isolado deve dar conta de suas manifestações insanas que não são aceitas no âmbito escolar", no familiar ou em outro contexto que a criança frequente.

Ainda considerando a expressão do neuropediatra, encontra-se a preocupação em relação ao aluno que apresenta características clínicas de TDAH e chama a atenção acerca do cuidado para que a criança não sofra desnecessariamente, visto que existem recursos disponíveis para esses alunos. "A coisa mais importante é não deixar a criança sofrendo à toa na escola, precisa ser avaliada, ela tem baixo rendimento por algum motivo, tem que ser avaliada..." (NP).

Percebemos que o fato deste profissional mostrar-se atento ao sofrimento do paciente constitui uma prática de cuidado importante, voltada ao bem-estar dos que chegam para atendimento. Isto porque o seu trabalho em conjunto com o dos demais profissionais que compõem a rede de atendimento multidisciplinar pode contribuir para que o aluno possa restabelecer suas relações com o aprender na escola e nos contextos em que se inter-relaciona.

As significações dos "profissionais da escola e da saúde" evidenciam as marcas do discurso determinista e associamos esse modo de atribuírem sentido à pessoa com TDAH aos mecanismos de risco, pois refletem nas relações do aluno com seus pares e com o saber. Entende-se que essa caracterização dos adultos conota um tipo de sentença ao aluno, uma vez que 'ser TDAH' indica um estado permanente, que demanda ao sujeito apenas assumir a condição.

$\mathrm{Na}$ percepção do grupo de 'familiares', o comportamento do filho é tão reprovável como escutam falar. Estes afirmam que corrigem o filho e também indicam que pode constituir uma fase do desenvolvimento infantil. Também mencionam a 
questão afetiva presente na relação com o filho. "Aqui ele é normal, porque num tem isso de criança que num faz arte na vida, né? Na hora a gente fica bravo com ele, daí ele não fai mais tamém" (F2), "Diz que morde os aluno. Em casa ele não é assim. É carinhoso. Eu também fui criança. Pensa numa criança artera que eu era. Só hoje eu sô uma pessoa normal, acredito que são fasef" (F9).

Observamos, também, que os familiares não associam o comportamento do filho a um tipo de disfunção biológica que demanda tratamento médico. Entendemos que esse discurso passa a ser reproduzido em decorrência do contato com pessoas que adotam o discurso biologizante. "Daí a professora um dia chamô e falô: 'Você tem que ir lá pra vê o quê que a gente vai fazer com o guri. Daí fui e eles falaro assim: 'O seu muleque tem pobrema"” (A3). "Foi quando a professora começo falá pra mim fazê um elétrico na cabeça. Até que eu levei e deu pobrema mesmo" (F8).

A procura por ajuda, segundo os relatos de A3 e A8, foi motivada pelo ingresso da criança na escola, indicando a necessidade de atendimento especializado. Sobre o fato de a família não perceber o comportamento 'anormal' apresentado como assunto médico, segundo Luengo (2009, p. 15), “Os pais, influenciados pelas queixas dos educadores, passam a procurar por ajuda médica e psicológica com o intuito de sanar tais comportamentos considerados anormais, o que acarreta na medicalização, que surge como principal meio de 'solucionar' o problema".

Aos refletirmos sobre a presença dos fatores de risco e proteção existentes nos contextos, valendo-nos das inter-relações que os sujeitos estabelecem, percebemos que a atitude dos pais de chamar a atenção, explicando as consequências do ato reprovável, constitui proteção. Evidencia-se, que, de fato, rever as práticas educativas constitui uma boa estratégia para a mudança de comportamento.

Os dados indicam que aos pais é apresentada a busca pelo diagnóstico e pelo laudo do neuropediatra não como alternativa, mas que ele está atrelado à condição de acesso e permanência do aluno na escola. O poder do laudo confere às partes envolvidas no processo diagnóstico o sentido de "acalmar os conflitos que um aluno que nãoaprende-na-escola gera" (COLLARES; MOYSÉS, 2011, p. 10). Esse efeito tranquilizador conferido pelo laudo às relações pode, assim, comprometer o processo de aprendizagem, 'simplesmente' porque não há o que ser feito e as relações passam a ser remediadas.

$\mathrm{Na}$ busca de apreender se os alunos participantes tinham dificuldade para aprender o que é ensinado na escola, vários responderam que sentem tal dificuldade: “A 
única dificuldade que eu tenho é Português... (A2), "Só de vez em quando na escola tem umas continhas" (A3), "As conta de dividir" (A4). Entretanto, as respostas destes sujeitos permitem observar que demonstram ter expectativas positivas em relação à possibilidade de aprender. Estas expectativas representam aspectos importantes para a análise dos processos e o modo como se relacionam consigo mesmos e com a aprendizagem na escola.

\section{Significados atribuídos aos procedimentos adotados}

Do mesmo modo como apresentamos um recorte das principais significações extraídas das falas dos diferentes grupos de participantes do estudo referente aos alunos com TDAH, apresentamos, agora, os significados produzidos neste contexto, acerca do modo como são percebidos os procedimentos adotados, desde o encaminhamento até o uso da medicação.

As significações dos 'profissionais da educação' anunciam a existência de uma rede de apoio e procuram assegurar que os encaminhamentos aos 'profissionais da saúde' só ocorram após 'observarem bem' o processo de aprender do aluno na sala de aula e a realização da anamnese com a família. " [...] Nós encaminhamos só depois de muita investigação, de muita observação... No caso, para psicóloga, fonoaudióloga e neuropediatra" (PE5). "Primeiro a gente vê a dificuldade de aprendizagem do aluno. [...] Daí encaminha pra psicóloga. Ai você já sente a necessidade... de medicamento" (P6).

O processo de sondagem realizado por estes profissionais pode favorecer a localização de dificuldades que não tinham sido percebidas nas interações com o aluno no cotidiano ou confirmar a ideia de que ele realmente precisa de atendimento especializado, o que nos faz crer na possibilidade de que as ações destes profissionais constituem proteção.

Poletto e Koller (2008) afirmam que os fatores de proteção são relevantes ao processo, pois permitem contrabalançar o risco que a circunstância favorece. Assim, a trajetória da pessoa pode ser alterada em virtude de experiências de cuidado e superação.

A psicóloga (PS) relatou que, inicialmente, avalia o aluno e realiza o “[...] aconselhamento aos pais, de professores, acompanhamento acadêmico” (PS). Entendemos que, assim como os profissionais da escola, a PS tem o cuidado de 
investigar o que pode estar acontecendo no processo de aprendizagem vivenciado pela criança na escola.

O neuropediatra comenta que, no atendimento que realiza, costuma conversar com o paciente, com o fim de amenizar o efeito negativo que, em regra, é associado à consulta médica. "Eu tenho o hábito sempre de cumprimentar os pacientes pequenos, a partir dai eles relaxam" (NP).

$\mathrm{O}$ relato do NP indica que a relação médico-paciente parece ser pautada na confiança e segurança. Isto posto, o cuidado do profissional de estabelecer vínculo com seus pacientes (crianças e adolescentes) pode ser considerado fator de proteção.

O participante NP acrescenta que realiza aconselhamento aos pais e orientação à escola sobre como proceder. "Não é só aconselhamento... Oriento a escola como lidá, como direcionar a parte pedagógica. Passo sites, livros, links que pode entrar pra aumentar o seu nível de conhecimento" (NP). A fala do participante revela o tom de compromisso com o paciente, ao relatar que orienta a escola sobre como direcionar as questões pedagógicas do professor, o que nos parece constituir um fator de proteção.

No que tange à frequência dos atendimentos aos alunos que apresentam queixas relacionadas à aprendizagem, as falas de PS e NP nos indicaram que eles são esporádicos. De acordo com a psicóloga, são condicionados pela necessidade de atendimento que se manifestam no cotidiano escolar. "Não existe um tempo, mas à medida que é necessário, que a professora, a diretora percebe que existe alguma intercorrência e que é preciso então retornar" (PS), "Em média de dois a quatro meses de retorno, depende de cada caso..." (NP).

De acordo com a perspectiva bioecológica, as intervenções supõem atividades regulares que devem acontecer em períodos prolongados de tempo, para que seja possível pensar o desenvolvimento humano. Quando as atividades são irregulares e descontinuadas, elas inviabilizam a formação de vínculos entre as pessoas e a promoção do desenvolvimento pode ser comprometida (YUNES; JULIANO, 2010).

Nesse sentido, as ações descontinuadas de acompanhamento do aluno por parte do psicólogo e do neuropediatra podem ser associadas a fatores de risco, impedindo que os avanços e as conquistas do paciente sejam conhecidos. É por essa razão que o modelo Bioecológico faz alusão ao exossistema e macrossistema, indicando que as políticas públicas devem ser favorecedoras da formação de redes de apoio. No caso deste estudo, as ações dos profissionais da saúde e da educação são norteadas por 
políticas que não favorecem a constituição de redes, embora haja vários profissionais envolvidos no atendimento.

Contudo, verificamos a preocupação de continuidade e de verificação da evolução do tratamento nas falas de PS e NP. Essa postura proativa em direção a um atendimento multidisciplinar pode desencadear ações que constituam fatores de proteção nesse contexto.

Em relação às trocas de informações com a família e com os profissionais da saúde envolvidos no processo diagnóstico, alguns "profissionais da educação" (Pedagogos) declararam que há familiares que estão preocupados com o filho, ao passo que outros não percebem essa necessidade. "Aqueles alunos que a família é desestruturada, né. Já não está nem aí com o filho [...]” (PE2).

Na compreensão de PE2, a troca de informações com a família a respeito do aluno com TDAH nem sempre acontece, por causa de sua configuração e condições objetivas. A crença arraigada nos polos 'família estruturada: pai, mãe e filhos X família desestruturada: outros arranjos familiares' é a explicação dada pelos professores para a inexistência de um processo coeso no acompanhamento do aluno. Patto (1992), ao denunciar o discurso da carência cultural, faz referência a esta questão:

Esta representação pejorativa dos pobres, gerada do lugar social da classe dominante e em consonância com seus interesses, foi encampada pela Psicologia e pode ser encontrada na teoria da carência cultural quando ela afirma que o ambiente familiar na pobreza é deficiente (PATTO, 1992, p. 111).

Tais formas de pensar sinalizam risco ao processo de aprender, pois é naturalizada a ideia de que 'não dá certo' e que investir esforços nesse sentido é em vão, dadas as características tipificadoras que a família possui: desestruturada e carente economicamente.

Em contrapartida, os professores percebem a família como parceira no processo de troca de informações acerca do aluno com TDAH. Isto porque as visitas de alguns pais não se resumem às solicitações da escola. Os participantes também se referem às trocas que acontecem fora do espaço escolar, o que leva a serem associados aos tipos presente e participativo. "Nas reuniões quando tem ele vem, quando eu chamo ele vem. Mas de vez em quando ele vem também, sabe... ele é um pai preocupado, bem presente" (P4), “A gente tá sempre em contato, sim. [...] Às vezes, a mãe me encontra na rua e 
fala: 'Oh professora, tá assim, assim'... Sempre que precisa a gente liga pra ela, ela vem na escola" (P6).

O modo como a família é percebida pelos professores no referido processo constitui proteção, segundo o presente aporte teórico, pois tais sentidos podem modificar o modo como os sujeitos se inserem no processo e dele participam.

No que tange à comunicação entre os profissionais envolvidos no processo diagnóstico, os "profissionais da educação" declararam que o contato com o psicólogo é mais aproximado (reuniões, relatório e recados) e com o neuropediatra mais distante, pois acontece somente via de relatório. “[...] com a psicóloga eu converso e envio os relatórios e com o neuropediatra é relatório” (PE4), “[...] dizer assim que eu li um relatório do psicólogo ou do neuropediatra que atendeu ele e mandou pra nós, não, nunca li” (P4), "eu não tenho muito contato com a psicóloga. O neuro das minhas crianças, sinceramente, eu não sei quem é” (P5).

Os dados evidenciam que a comunicação existente (via relatórios) é insuficiente. Reconhecemos que o relatório tenha vários pontos positivos, pois contempla o que já foi feito, as intencionalidades de intervenção, as demandas, além de nortear as discussões conjuntas. Entretanto, não substitui as trocas interpessoais.

Barbarini (2011) assinala que o relatório possibilita encurtar a distância entre os profissionais, também refere que ele assume o sentido de controle sobre o comportamento da criança e reduz a necessidade de que ela tenha voz no processo diagnóstico. A observação anterior ajuda a pensar que nem sempre o relatório é utilizado em favor do desenvolvimento da pessoa.

Consideradas tais questões, o modo como são significadas as trocas que acontecem entre os profissionais que compõem a rede de atendimento faz despontar tanto fatores de risco como de proteção. O risco aparece na relação verticalizada que define a comunicação entre os envolvidos no processo diagnóstico, que não passa despercebida aos participantes (professores). E a proteção se manifesta por deixar subentendida a necessidade de rever as práticas que são traduzidas no trabalho da rede, a fim de que ela possa ser fortalecida e todos os participantes possam realizar trabalho eficaz.

No que tange à comunicação entre os sujeitos envolvidos no processo diagnóstico, o neuropediatra (NP) argumenta: “Eu já sei as perguntas que eu tenho que fazer, eu tenho as perguntas direcionadas e a família ajuda. Alguns casos de pais que 
têm um nível sociocultural muito baixo, esses vão ter dificuldade de dar um direcionamento".

A fala do NP nos permite inferir que existe uma barreira linguística existente entre ele e a família. Parece constituir risco o modo como o neuropediatra significa sua relação com a família, pois, de certo modo, o isenta de empenhar-se para explicar, dada a crença de que ela não vai compreender o que ele tem a dizer. A linguagem falada foge à função de comunicação para constituir-se como instrumento de poder (BOURDIEU, 1983).

A família procura formas de lidar com as solicitações dos profissionais da escola e da saúde. Os relatos anunciam a resistência em aceitar o encaminhamento do aluno: “Tomô os trinta dias. Fiquei com medo. Fui dano só meio, quase o mês intero" (F1), assim como a negligência da escola por não ter realizado os encaminhamentos que a família entende como necessários: "Não houve apoio da escola. A professora se recusou e alegou que ele não tinha nada" (F4).

Identificamos, nesse processo, risco e proteção se contrapondo. Podem ser representativos de risco: a resistência da família quando, de fato, o aluno precisa de atendimento e a busca pelo diagnóstico quando se torna uma constante entre as famílias que afirmam não dar conta do filho. Em contrapartida, a resistência da família pode ser proteção quando se sente ameaçada e insegura no processo, e, em especial, quando o medicamento assume o protagonismo em detrimento do aluno e seu processo de desenvolvimento.

Outros sentidos de risco e proteção se manifestam: risco quando em lugar de ampliar o universo de informações acerca do que tem desencadeado os sintomas de TDAH, ele amplia as possibilidades de fechar o diagnóstico. Sentido de proteção, quando o encaminhamento para o especialista da neuropediatria constitui o apoio que algumas famílias precisam para melhorar as relações com suas crianças/adolescentes e para se sentirem cuidados como pais, diante de uma demanda difícil a ser conduzida.

Todos os 'profissionais da educação' entrevistados afirmaram que há melhoria na aprendizagem dos alunos após o uso do medicamento: "começou a despertar"; "facilidade de concentrar"; "agora está aprendendo"; "pegou interesse"; "quer aprender"; "perdia a memória muito rápido"; "faz com que o aluno pare"; "estão mais calmos"; "tranquilinho"; "não atrapalha ninguém"; "realiza as atividades propostas pelo professor", "presta atenção no professor", "socialização". 
As representações destes participantes expressam efeitos de competência, os quais favorecem o engajamento do aluno na realização de atividades em sala de aula. Nesse sentido, medicamento pode ser representativo de proteção, pois o aluno passa a apresentar melhoras em algumas condições de aprender.

O medicamento parece assumir sentido 'messiânico' diante do aprender. Na condição de que o aluno esteja 'saudável', tudo é possível, pois são suas forças internas que ditam a possibilidade de aprendizagem (ASBHAR; NASCIMENTO, 2013). Contudo, quando o medicamento é tomado como um garantidor da aprendizagem pode se constituir risco, pois o processo de aprender demanda um conjunto de aspectos, que vão além das condições 'saudáveis' da pessoa.

A psicóloga entrevistada relata que o uso do medicamento pelo aluno ocorre mediante prescrição médica. "A gente encaminha pro neuro, é ele que faz a prescrição do medicamento" (PS). O neuropediatra informa que a condição inicial para que ela seja realizada é a suspeita de que a criança apresente o TDAH: “[...], primeiro eu tenho que ter uma suspeita de que a criança tem TDAH. Eu sempre falo que o remédio é o primeiro passo, o segundo passo são as intervenções multidisciplinares, a participação da família [...]” (NP). O neuropediatra faz alusão à importância do atendimento de outros profissionais, das trocas com a família, paralelo ao tratamento medicamentoso.

Sobre a relação do medicamento com a aprendizagem, a PS apontou elementos que ultrapassam o sucesso acadêmico, pois alcançam a construção da identidade do aluno. O NP indicou a atenção como a principal beneficiada, dada a melhoria da: "memória"; "persistência"; "percepção"; "coordenação motora"; "ritmo"; a "capacidade interpretativa" (NP).

Os familiares também declaram que o remédio interfere positivamente na aprendizagem, sendo associado à melhora da atenção. No entanto, a fala de F9 nos faz refletir acerca das consequências da retirada do medicamento: "Se ele largá, eu penso comigo que aí ele não vai fazê nada mais na escola. Porque ele não fazia nada antes, primera e segunda série repetiu” (F9).

A participante F9 afirma ter receio de que sem o uso do medicamento o filho possa retroceder em relação aos estudos. Entendemos que a possibilidade de ter que fazer uso do medicamento para o resto da vida seja de risco, pois parece gerar angústia aos pais, visto que o remédio aparenta ser a única forma de aprender que é anunciada pelos profissionais da escola e da saúde. 
Perguntamos aos alunos se faziam uso de medicamento, qual era o nome dele e o motivo. Todos os participantes afirmaram que usavam e souberam nomeá-lo, mas nem todos souberam relatar o motivo de ter que utilizá-lo, como nos casos: "O médico não explicô muito bem não, mais ele falô que eu tenho que toma pro resto da minha vida. Vinte, trinta, quarenta, sessenta ano" (A2), "Eu só sei que eu tenho que tomá" (A4).

Considerando que a faixa etária dos alunos que tomam o medicamento está entre seis e treze anos de idade, o fato de se tratar de um medicamento de uso contínuo que perpassa o processo de desenvolvimento desses sujeitos precisa ser questionado, sobretudo em razão dos possíveis efeitos fisiológicos acarretados pelo uso continuado da medicação.

Nesse sentido, identificar os fatores de risco e proteção constitui tarefa importante para compreender como se encontram 'organizadas' as relações que permeiam o processo diagnóstico e permite evidenciar a resiliência em contexto. Isto porque a resiliência consiste em um processo elaborado com base na relação riscoproteção, que não se excluem, mas favorecem o movimento de reconstrução de um dado evento.

O equilíbrio de forças se manifesta conforme as significações dos participantes permitiram observar, visto que cada um deles, a seu modo, tem se mostrado ocupado e preocupado em fazer o melhor para que o aluno possa se desenvolver e inserir-se da melhor forma nos contextos, mesmo diante das limitações presentes no processo que nos foi relatado.

\section{Considerações finais}

As significações dos participantes revelaram a prevalência de discursos tipificadores do sujeito que possui o diagnóstico de TDAH. Os rótulos empregados ao aluno com TDAH, apontados pelos grupos de participantes, podem ser associados às disposições inibidoras que, muitas vezes, representam entraves ao processo de desenvolvimento da pessoa, conforme sugere a lista de atributos negativos indicados pelos participantes para definir o aluno com TDAH: agitado, agressivo, indisciplinado, 'estabanado', ameaça ao ambiente e aos colegas.

Entretanto, risco e proteção também são encontrados no contexto de diagnóstico e de encaminhamento. As ações dos envolvidos revelam nuances da formação que possuem, da visão acerca do TDAH, da aprendizagem e dos familiares. Tudo isso se 
alia às políticas públicas norteadoras do funcionamento da rede nesses espaços de atendimento e constitui o contexto no qual os sentidos são produzidos e passam a garantir as ações nesses espaços.

Os resultados do estudo levaram à compreensão de que o uso de medicação por alunos nem sempre constitui risco ao processo de aprendizagem. O questionamento se volta àquelas questões nas quais o uso de medicamentos representa a condição de acesso e permanência do aluno na escola, em que as estratégias de abordagem à família são coercitivas e levam-na a acreditar que o medicamento consiste no único recurso favorecedor do sucesso escolar do seu filho. Isto porque essa concepção, muitas vezes, anuncia o empoderamento do diagnóstico e do remédio em relação ao paciente.

O referencial teórico adotado colaborou na revisão de determinados conceitos acerca do processo de aprender e não aprender. Isto em razão dos equívocos que são cometidos, ao realizar uma leitura superficializada que, muitas vezes, vitimiza o aluno e culpabiliza ora os pais, ora os professores, ora os profissionais da saúde, pelas adversidades que permeiam o processo de aprender. E, paralelamente a estas questões, os processos que constituem as inter-relações em contexto são ignorados, como se não produzissem qualquer efeito sobre o processo de aprender na sala de aula.

Entretanto, opor-se à necessidade de tratamento medicamentoso a todos os sujeitos nos parece igualmente prejudicial. Escapar a essa lógica torna-se possível quando consideramos os fatores de risco e proteção presentes em processo, os quais nos ajudam a pensar as expressões de resiliência em contexto e as possibilidades de enfrentamento. Exercitar o olhar para aspectos sadios e de sucesso pode ajudar a pensar a resiliência como processo, além de evitar as classificações e/ou rotulações que são determinadas ideologicamente.

\section{REFERÊNCIAS}

ASBAHR, Flávia da S. F.; NASCIMENTO, Carolina P. Criança não é manga, não amadurece: conceito de maturação na teoria histórico-cultural. Psicologia: Ciência e Profissão, Brasília, v. 33, n. 2, p. 414-427, 2013.

BARBARINI, Tatiana de Andrade. A medicalização da vida e os mecanismos de controle: reflexões sobre o Tdah. Plural, São Paulo, v. 18, n. 1, p. 93-115, 2011.

BAZONI, Jane Esther da Silva. O significado do não aprender na sala de apoio à aprendizagem: a resiliência na voz dos protagonistas do mesossistema constituído pela 
família e escola. 2014. 187 f. Dissertação (Mestrado em Educação) - Universidade Estadual de Londrina, Londrina, 2014.

BENETTI, Idonézia Collodel.; CREPALDI, Maria Aparecida. Resiliência revisitada: uma abordagem reflexiva para principiantes no assunto. Revista Electrónica de Investigación y Docencia (REID), v. 7, p. 7-30, jan., 2012.

BONADIO, Rosana Aparecida Albuquerque. Problemas de atenção: implicações do diagnóstico de TDAH na prática pedagógica. 2013. 253 f. Tese (Doutorado em Educação) - Universidade Estadual de Maringá, Maringá, 2013.

BOURDIEU, Pierre. A economia das trocas linguísticas. In: ORTIZ, Renato. (Org.). Pierre Bourdieu: Sociologia. São Paulo: Ática, 1983. p. 1-97. (Coleção Grandes Cientistas Sociais).

COLLARES, Cecília Azevedo Lima.; MOYSÉS, Maria Aparecida Affonso.

Preconceitos no cotidiano escolar: a medicalização do processo ensino-aprendizagem. In: CONSELHO REGIONAL DE PSICOLOGIA DE SÃO PAULO - GRUPO INTERINSTITUCIONAL QUEIXA ESCOLAR. (Orgs.) Medicalização de crianças e adolescentes: conflitos silenciados pela redução de questões sociais a doenças de indivíduos. São Paulo: Casa do Psicólogo, 2011. p. 193-213.

CYRULNIK, Boris. Resiliência: essa inaudita capacidade de construção humana. Lisboa: Ed. Instituto Piaget, 2001.

GIL, Antonio Carlos. Métodos e técnicas de pesquisa social. 6 ed. São Paulo: Atlas, 2008.

ITABORAHY, Cláudia. A ritalina no Brasil: Uma década de produção, divulgação e consumo. 2009. 126 f. Dissertação (Mestrado em Saúde Coletiva) - Instituto de Medicina Social, Universidade do Estado do Rio de Janeiro, Rio de Janeiro, 2009.

LARAIA, Roque de Barros. Cultura: um conceito antropológico. 14 ed. Rio de Janeiro: Jorge Zahar, 2001.

LIBÓRIO, Renata Maria Coimbra. Escola: risco, proteção e processos de resiliência durante a adolescência. In: REUNIÃO ANUAL DA ANPED, 32. 2009, Caxambú. Anais eletrônicos... Timbaúba: Espaço Livre, 2009. v. 1, p. 1-16. Disponível em: <http://32reuniao.anped.org.br/ arquivos/trabalhos/GT20-5283--Int.pdf >. Acesso em: 7 maio 2015.

LUENGO, Fabiola Colombani. A vigilância punitiva: a postura dos educadores no processo de patologização e medicalização da infância. 2009. 120 f. Dissertação (Mestrado em Psicologia) - Faculdade de Ciências e Letras, Universidade Estadual Paulista, Assis, 2009.

MORAIS, Normanda Araujo de.; KOLLER, Silvia Helena. Abordagem ecológica do desenvolvimento humano, Psicologia positiva e resiliência: ênfase na saúde. In: KOLLER, Silvia Helena (Org.). Ecologia do desenvolvimento humano: pesquisa e intervenção no Brasil. São Paulo: Casa do Psicólogo, 2004. p. 95-111. 
OLIVEIRA, Francismara Neves.; MACEDO Lino. Resiliência e insucesso escolar: uma reflexão sobre as salas de apoio à aprendizagem. Revista Estudos e Pesquisas em Psicologia, Rio de Janeiro, v. 11, n. 3, p. 983-1004, 2011.

PATTO, Maria Helena Souza. A família pobre e a escola pública: anotações sobre um desencontro. Psicologia USP, São Paulo, v. 3, n. 1-2, p. 107-121, 1992.

POLETTO, Michele.; KOLLER, Silvia Helena. Contextos ecológicos promotores de resiliência: fatores de risco e proteção. Estudos de Psicologia, Campinas, v. 25, n. 3, p. 405-416, jul./set., 2008.

SCRIPTORI, Carmem Campoy.; BORGES JUNIOR, Jair Fortunato. Discriminação e preconceito como fatores de violência e atitudes docentes como fator de promoção de resiliência na escola. Revista do Centro de Educação da UFSM, Santa Maria, v. 35, n. 3, p. 431-448, 2010.

YUNES, Maria Angela Mattar. Psicologia positiva e resiliência: o foco no indivíduo e na família. Psicologia em Estudo, Maringá, v. 8, n. esp., p. 75-84, 2003.

YUNES, Maria Angela Mattar.; JULIANO, Maria Cristina. A Bioecologia do Desenvolvimento Humano e suas interfaces com educação ambiental. Cadernos de Educação (FaE/PPGE/UFPel), Pelotas, n. 37, p. 347-379, set./dez., 2010.

YUNES, Maria Angela Mattar.; MIRANDA, Angela Torma.; CUELLO, Sandra Eliane Sena. Um olhar ecológico para os riscos e as oportunidades de desenvolvimento de crianças e adolescentes institucionalizados. In: KOLLER, Silvia Helena (Org.).

Ecologia do desenvolvimento humano: pesquisa e intervenção no Brasil. São Paulo: Casa do Psicólogo, 2004. p. 201-222.

YUNES, Maria Angela Mattar.; SZYMANSKI, Heloísa. Resiliência: noção, conceitos afins e considerações práticas. In: TAVARES, José Pereira da Costa. Resiliência e educação. 3 ed. São Paulo: Cortez: 2002. p. 13-42.

\section{Como referenciar este artigo}

SANTOS, Regina Lemes dos.; OLIVEIRA, Francismara Neves de.; BIANCHINI, Luciane Guimarães Batistella. Medicalização da Aprendizagem e Resiliência: significações produzidas na escola. Revista Ibero-Americana de Estudos em Educação, Araraquara, v. 13, n. 4, p. 1792-1813, out./dez., 2018. E-ISSN: 1982-5587. DOI: 10.21723/riaee.unesp.v13.n4.out/dez.2018.10190

Submissão em: 30/07/2017

Revisões requeridas: 07/19/2017

Aprovação final em: 06/11/2017 